\title{
CONHECIMENTO DE ACADÊMICAS DE ENFERMAGEM SOBRE DISFUNÇÕES SEXUAIS FEMININAS
}

\author{
NURSING ACADEMICS KNOWLEDGE ABOUT THE SEXUAL DISFUNCTIONS OF WOMEN \\ CONOCIMIENTO DE ACADÉMICAS DE ENFERMERÍA EN EL DISFUNCIONES SEXUALES \\ FEMENINAS
}

Nilza Alves Marques Almeida ${ }^{1}$, Luciana Alexandre da Silva ${ }^{2}$, Neide Maria de Araújo ${ }^{3}$

RESUMO: Este estudo, de caráter descritivo, objetivou identificar 0 conhecimento de acadêmicas de enfermagem sobre as disfunções sexuais femininas, bem como a sua importância para a formação profissional do enfermeiro. Aplicou-se um questionário estruturado a vinte e três acadêmicas da Faculdade de Enfermagem da Universidade Federal de Goiás e a trinta e sete da Universidade Católica de Goiás, que aceitaram participar do estudo. Constatou-se que o conhecimento das acadêmicas de enfermagem sobre as disfunções sexuais femininas, em ambas as instituições, é parcial e insuficiente, devido ao conteúdo não ser abordado na graduação pela especificidade. Quanto à importância para a formação profissional do enfermeiro, constatou-se a necessidade de sua abordagem para atuação na assistência à saúde da mulher. Concluiu-se que é pertinente a introdução de uma disciplina sobre sexualidade humana no curso de graduação em enfermagem, para que o profissional enfermeiro promova assistência global à saúde da mulher.

PALAVRAS-CHAVE: Sexualidade; Enfermagem Obstétrica; Saúde da Mulher.

ABSTRACT: This descriptive study identified the nursing academics knowledge of women's sexual dysfunctions, as its importance for the nurse professional background. It was applied as a structured questionnaire to twenty-three academics at the Nursing Faculty of the Goiás Federal University and to thirtyseven at the Goiás Catholic University, that agreed to participate in the research. It was verified that the nursing academics knowledge about women's sexual dysfunctions, on both universities, is partial and insufficient because the content is not approached at the graduation by the specificity. The nurse professional background approach is very important to the nurse in order to assist the woman's health. We concluded that the introduction of a discipline about human sexuality at the Nursing graduation course is pertinent for the professional nurse to assist the health of women.
KEYWORDS: Sexuality; Obstetrical Nursing; Women's Health.

RESUMEN: Este estudio, de carácter descriptivo, objetivo identificar el conocimiento de académicas de enfermería sobre las disfunciones sexuales femeninas, así como su importancia para la formación profesional del enfermero. Se aplicó un cuestionario estructurado a veintitrés académicas de la Facultad de Enfermería de la Universidad Federal de Goiás y la treinta y siete de la Universidad Católica de Goiás, que hubieron aceptado participar del estudio. Se constató que el conocimiento de las académicas de enfermería en el disfunciones sexuales femeninas, en ambas instituciones, es parcial y insuficiente, debido al contenido no ser abordado en la graduación por la especificidad. Cuanto a la importancia para la formación profesional del enfermero, se constató la necesidad de su abordaje para actuación en la asistencia a la salud de la mujer. Se concluyó que es pertinente la introducción de una disciplina sobre sexualidad humana en el curso de graduación en enfermería, para que el profesional enfermero promueva asistencia global a la salud de la mujer.

PALABRAS-CLAVE: Sexualidad; Enfermería Obstétrica; Salud de las Mujeres.

1. Enfermeira. Mestre em Biologia. Professora Assistente da Faculdade de Enfermagem da Universidade Federal de Goiás. Doutoranda no Porgrama de Pós Graduação - Doutorado - em Ciências da Saúde / Convênio Rede Centro Oeste: UnB/UFG/UFMS. Contatos: nilza@fen.ufg.br; endereço: Rua 227-A, nº. 72, apto. 804, Residencial Arapoema, Setor Universitário, CEP: 74610155 Goiânia (GO).

2. Enfermeira do Programa de Saúde da Família. e-mail: luardamadrugada@hotmail.com

3. Enfermeira do Programa de Saúde da Família. e-mail: neiria@zipmail.com.br 


\section{INTRODUÇÃO}

A sexualidade humana é extremamente complexa. Trata-se de questões relacionadas tanto aos aspectos orgânicos quanto aos fatores biopsicossociais. Historicamente, há grandes controvérsias e interpretações errôneas quanto ao sexo e à sexualidade. Por isso, apresenta-se ainda repleta de regras e tabus, mesmo pela função sexual ter deixado de estar voltada à procriação.

Segundo DIAMANTINO (1993), a sexualidade transcende definições físicas e refere-se ao impulso e à emoção que a proximidade do sexo pode produzir. Para entender a sexualidade, segundo FOUCAULT (1980), KAPLAN (1977), CAVALCANTI (1992), DIAMANTINO (1993), BUENO (2001) e GIR et al (2000), necessita-se de uma análise minuciosa, por que ela faz parte de um processo contínuo que inicia na concepção e percorre todo o ciclo da vida, recebendo influência direta e constante de múltiplos fatores. As marcas da repressão sexual, passadas de geração a geração, tem impedido que a sexualidade seja vivenciada com naturalidade e aceita como as demais necessidades humanas básicas.

De acordo com BUENO (2001) e MANNOCCl (1995), os problemas relacionados à sexualidade, condicionados aos fatores históricos, políticos, sociais, culturais, religiosos e educacionais, têm influenciado consideravelmente no comportamento e nas atitudes dos indivíduos, diante de padrões morais e valores rigidamente pré-estabelecidos, causando graves conseqüências para a saúde em geral, como os distúrbios psicossomáticos. Esses distúrbios da esfera sexual, conforme MANNOCCI (1995) são divididos em três grupos: disfunções, inadequações e desvios.

DIAMANTINO (1993) descreve as disfunções sexuais como distúrbios da resposta sexual. KAPLAN (1977) refere que eles envolvem os distúrbios do desejo, excitação e orgasmo, e classifica disfunções sexuais femininas em inapetência sexual, anorgasmia, dispareunia e vaginismo.

Segundo CAVALCANTI (1992), "inapetência sexual é a ausência de desejo sexual. Anorgasmia é a falta de orgasmo. Dispareunia é a dificuldade no coito expressa pela dor na relação sexual. Vaginismo é o espasmo dos músculos perineais, impedindo total ou parcialmente a penetração na vagina, impossibilitando ou dificultando o coito e o exame ginecológico".

Conforme ABDO (2000), até o século XVIII, acreditava-se que as disfunções sexuais se originavam de elementos externos ao indivíduo. A conduta sexual adequada era ditada pela igreja e pelos bons costumes. Disfunções e perversões sexuais, embora conhecidos há milênios, apenas no século $X X$ foram classificados como quadros patológicos.

MASTERS \& JOHNSON (1979) apud SILVEIRA (1993), após várias pesquisas, estimaram que problemas sexuais de qualquer natureza ocorrem em $50 \%$ dos casais que têm vida sexual ativa. MANNOCCl et al (1992) apud SILVEIRA (1993), estudando um grupo de 500 pacientes sem queixa sexual prévia, constataram que $45 \%$ das mulheres eram anorgásmicas. NEIVA (2002) constatou que 54\% das brasileiras apresentavam algum tipo de problema sexual. Diante desses dados, NEIVA (2002) relata que a sexualidade se tornou um dos quatro parâmetros utilizados pela Organização Mundial de Saúde para definir a qualidade de vida de uma pessoa.

A sexualidade é uma dimensão importante do ser humano, incluída entre as necessidades humanas básicas, sendo essencial no atendimento holístico.

Segundo FERREIRA \& FIGUEIREDO (1997), a enfermagem entendida como ciência e arte de cuidar de seres humanos deve considerar o ser em sua integridade, possuidor de necessidades psíquicas, sociais, biológicas e espirituais.

Teoricamente, a enfermagem ressalta o atendimento das necessidades de saúde do homem no seu âmbito global, mas as questões voltadas ao emocional não estão claras. Não há discussão crítica e contextualizada sobre a amplitude do processo da sexualidade humana, fundamental para a autocompreensão e sucesso profissional.

TAVARES (1985) apud GIR et al (2000) consideram ser o enfermeiro o profissional mais indicado para desempenhar a função de orientador sexual. Todavia, pesquisa realizada por PELÁ (1995) apud GIR et al (2000), detectou que os enfermeiros possuem conhecimentos e habilidades insuficientes para trabalhar a questão da sexualidade.

Conforme GARCIA (1993), BISON (1998) e GIR et al (2000), uma das razões para a aparente inabilidade do enfermeiro em abordar aspectos da sexualidade humana durante a assistência está relacionado à ausência desse conteúdo no currículo do curso de enfermagem.

De acordo com o artigo $1^{\circ}$ da Resolução $n^{\circ} 421$ de 1998 do Conselho de Ensino, Pesquisa, Extensão e Cultura da UFG (BRASIL, 1998a), o curso de graduação em enfermagem da Universidade Federal de Goiás visa formar o enfermeiro generalista voltado para a administração da assistência de enfermagem e da educação em saúde, com postura crítica e reflexiva, comprometida com as necessidades da população. Conforme parágrafo único, o enfermeiro generalista é aquele que dentro de uma visão holística, articula a especificidade com a globalidade do conhecimento e as relações inter e multidisciplinares. Segundo o artigo $2^{\circ}$, ao final do curso de graduação em enfermagem 0 aluno será capaz de compreender o homem como um ser em constante interação com o ambiente, considerando suas dimensões biológicas, sociais, psíquicas e transcendentais.

Nessa perspectiva, o fato da sexualidade humana não ser abordada em nenhum momento na grade curricular do curso de Graduação em Enfermagem, desperta para uma reflexão sobre o tema, em especial, sobre as disfunções sexuais femininas.

Os acadêmicos necessitam adquirir maior conhecimento sobre o processo de sexualidade nas 
diferentes etapas do ciclo vital, a fim de capacitaremse para o auto-entender, evitando problemas no exercício da sua própria sexualidade, e para a assistência à mulher com diagnóstico de disfunções sexuais.

ABDO (1984), em estudo realizado com universitários, observou a presença de problemas na esfera sexual em $80 \%$ dos entrevistados. Apesar dos universitários dominarem várias áreas desse conhecimento, observou-se que entre eles é grande o despreparo em assuntos relativos à sexualidade humana.

O enfermeiro é um profissional que tem oportunidade de trabalhar com os grupos em todas etapas do ciclo da vida. Assim, é necessário que ele tenha conhecimento suficiente do processo de sexualidade.

De acordo com a Declaração dos Direitos Sexuais aprovada durante o XV Congresso Mundial de Sexologia, ocorrido na China em 1998, saúde sexual é um direito fundamental.

Como a sexualidade humana consiste em um assunto muito amplo, neste estudo serão abordadas somente as disfunções sexuais femininas por exercerem importante influência na evolução da sexualidade desse gênero, como, também, pelo curso de enfermagem ter predominância feminina e por se tratar de uma profissão que assiste diretamente ao paciente/cliente, tanto no âmbito hospitalar como ambulatorial.

\section{OBJETIVOS}

- Identificar o conhecimento de acadêmicas de enfermagem sobre Disfunções Sexuais Femininas

- Verificar a importância desse conhecimento para a formação profissional do enfermeiro.

\section{METODOLOGIA}

Trata-se de uma pesquisa de campo, descritiva, com abordagem quanti-qualitativa, realizada no período de abril a novembro de 2002, nas Faculdades de Enfermagem das Universidades Federal de Goiás e Católica de Goiás.

Os critérios de inclusão para a amostra foram: ser acadêmica de enfermagem, estar no último ano da graduação, aceitar participar do estudo e assinar ao termo de consentimento livre e esclarecido.

O projeto foi submetido à aprovação do Comitê de Ética em Pesquisa Humana e Animal do Hospital das Clínicas da Universidade Federal de Goiás, protocolo n. ${ }^{\circ}$ 07/2002, atendendo a resolução 196/96 do Conselho Nacional de Saúde (BRASIL, 1998b).

$\mathrm{O}$ instrumento de coleta de dados constituiu-se de um questionário estruturado, contendo questões abertas e fechadas, que foi submetido à validação de conteúdo e analisado por três professores pesquisadores de áreas afins, quanto à pertinência, a abrangência, a organização lógica e a tendenciosidade dos itens (POLIT \& HUNGLER, 1995).

Após aprovação pelo Comitê de Ética em Pesquisa e validação do instrumento de coleta de dados, realizou-se um teste piloto para maior confiabilidade e operacionalização do instrumento.

A coleta dos dados foi realizada em sala de aula através do preenchimento do questionário, que depois de respondido, foi lacrado em um envelope garantindo o anonimato dos sujeitos da pesquisa.

Os dados foram apresentados em tabelas, com freqüências simples e percentuais, sendo analisados por meio de estatística descritiva.

\section{RESULTADOS E DISCUSSÃO}

\section{a) Perfil sócio-econômico-demográfico}

A amostra constituiu-se de sessenta acadêmicas dos cursos de graduação em enfermagem da Universidade Federal de Goiás e da Universidade Católica de Goiás, cujo perfil sócio-econômicodemográfico está descrito na Tabela 1.

Tabela 1. Perfil sócio-econômico-demográfico. Goiânia (GO), 2002.

\begin{tabular}{|c|c|c|c|}
\hline \multicolumn{2}{|l|}{ Características } & $\mathrm{F}$ & $(\%)$ \\
\hline \multirow[t]{2}{*}{ Instituição } & - UFG & 23 & 38,0 \\
\hline & - UCG & 37 & 61,7 \\
\hline \multicolumn{2}{|c|}{ Idade média em anos } & 24,6 & - \\
\hline \multirow{3}{*}{ Estado civil } & - Solteira & 49 & 81,7 \\
\hline & - Casada & 10 & 16,6 \\
\hline & - União consensual & 01 & 1,7 \\
\hline \multirow[t]{2}{*}{ Filhos } & $-\operatorname{Sim}$ & 11 & 18,3 \\
\hline & - Não & 49 & 81,7 \\
\hline \multicolumn{2}{|l|}{ Média de filhos } & 1,4 & - \\
\hline \multirow[t]{5}{*}{ Religião } & - Católica & 31 & 51,6 \\
\hline & - Espírita & 08 & 13,3 \\
\hline & - Evangélica & 11 & 18,3 \\
\hline & - Cristã & 02 & 3,3 \\
\hline & - Em branco & 08 & 13,3 \\
\hline Residência & - Goiânia & 55 & 91,7 \\
\hline
\end{tabular}




\begin{tabular}{|c|c|c|c|c|}
\hline & - Anápolis & 02 & 3,3 & \\
\hline & - Brasília. & 02 & 3,3 & \\
\hline & - Aparecida de Goiânia & 01 & 1,7 & \\
\hline \multirow{2}{*}{ Trabalha } & $-\operatorname{Sim}$ & 28 & 46,7 & \\
\hline & - Não & 32 & 53,3 & \\
\hline \multicolumn{4}{|c|}{ Atividade Profissional: } & \\
\hline & - Técnica de Enfermagem & 06 & 10,0 & \\
\hline & - Bolsista & 06 & 10,0 & \\
\hline & - Professora & 04 & 6,7 & \\
\hline & - Estagiária & 03 & 5,0 & \\
\hline & - Pesquisadora & 02 & 3,3 & \\
\hline & - Educadora social de rua & 01 & 1,7 & \\
\hline & - Auxiliar técnica de cálculos & 01 & 1,7 & \\
\hline & - Auditora de prontuário & 01 & 1,7 & \\
\hline & - Feirante & 01 & 1,7 & \\
\hline & - Auxiliar de enfermagem & 01 & 1,7 & \\
\hline & - Funcionária pública & 01 & 1,7 & \\
\hline & - Secretária auxiliar & 01 & 1,7 & \\
\hline
\end{tabular}

Entre as acadêmicas pesquisadas: $61,7 \%$ eram da UCG e 38,3\% da UFG. A idade média foi de 24,6 anos. $81,7 \%$ eram solteiras; $51,6 \%$ declararam-se católicas; 91,7\% residiam na cidade de Goiânia e $53,3 \%$ não exerciam atividade remunerada. Dentre as que exerciam $(46,7 \%)$, havia predomínio de técnicas de enfermagem $(10,0 \%)$ e bolsistas $(10,0 \%)$.

\section{b) Conhecimento de acadêmicas de enfermagem sobre disfunções sexuais femininas}

Do questionário aplicado, oito questões referiamse ao conhecimento das acadêmicas de enfermagem sobre disfunções sexuais femininas.

Quanto às respostas da primeira questão: "Qual o seu conceito sobre disfunções sexuais femininas?", apresentadas na Tabela 2, a maioria (65,0\%) das acadêmicas do curso de graduação em enfermagem definiu disfunções sexuais como dificuldade no exercício da sexualidade, alterações fisiológicas, dificuldade em sentir prazer no ato sexual, demonstrando assim, um conhecimento conceitual do assunto, embora parcial e superficial.

É importante ressaltar que algumas acadêmicas possuem uma noção de disfunção sexual voltada à fertilidade, à preferência por diferentes práticas sexuais e/ou a doenças sexualmente transmissíveis que, conceitualmente, não possuem nenhuma conotação com as disfunções sexuais femininas, demonstrando falta de conhecimento sobre o assunto.

Tabela 2. Conceito de acadêmicas de enfermagem sobre disfunções sexuais femininas. Goiânia (GO), 2002.

\begin{tabular}{lll}
\hline RESPOSTAS & $\mathrm{f}$ & $\%$ \\
\hline - Dificuldade no exercício da sexualidade & 28 & 46,7 \\
- Alterações fisiológicas & 11 & 18,3 \\
- Alterações hormonais & 05 & 8,3 \\
- Desconforto físico-mental & 02 & 3,3 \\
- Algo que afeta a fertilidade da mulher & 02 & 3,3 \\
- Alterações no comportamento sexual feminino & 01 & 1,7 \\
- Vulvovaginites & 01 & 1,7 \\
- Preferências por diferentes práticas sexuais & 01 & 1,7 \\
- Desconhecimento do seu próprio corpo/auto exame & 01 & 1,7 \\
- DST & 01 & 1,7 \\
- Patologias & 01 & 1,7 \\
- Questões culturais & 01 & 1,7 \\
-.Não souberam responder & 05 & 8,3 \\
\hline TOTAL & 60 & 100,0 \\
\hline
\end{tabular}

Segundo DIAMANTINO et al (1993), disfunção sexual é um distúrbio da resposta sexual, uma resposta sexual anormal. Tem como etiologia causas orgânicas, tais como, gênito-urinárias, infecciosas, neurológicas, vasculares, hematológicas e de efeitos de drogas como: diuréticos, hormônios, tranqüilizantes, sedativos, hipnóticos, bem como drogas ilícitas, problemas psicológicos e genéticos.
Pode ser primária, com ocorrência na primeira experiência sexual ou secundária, quando ocorre após prévia competência.

KAPLAN (1977) refere que as disfunções sexuais femininas podem ser divididas em quatro síndromes distintas: disfunção sexual geral, disfunção orgásmica, vaginismo e anestesia sexual ou conversão. Enquanto ABDO (2000), as divide em: 
ARTIGO ORIGINAL

vaginismo, dispareunia, anorgasmia e alterações da libido (ou distúrbios da fase de desejo ou frigidez).

Segundo KAPLAN (1977), disfunção sexual geral é a inibição do aspecto geral de excitação da resposta sexual. Disfunção orgásmica é o dano do componente orgásmico da resposta sexual da mulher. Vaginismo é o espasmo condicionado da entrada da vagina, impossibilitando a relação sexual. Anestesia sexual ou conversão é a ausência de sensação com a estimulação sexual. O autor destaca que uma pequena porcentagem destas são derivadas de causas físicas e a maioria é de origem psicológica.

MASTERS \& JOHNSON (1970) apud GARCIA (1993), relatam que a alteração do ciclo de resposta sexual determina a ocorrência de disfunções sexuais. Na mulher a disfunção mais freqüente é a anorgasmia.

De acordo com BUENO (2001), MANNOCCI (1995) e MURALHO apud BENTO (2000), os preconceitos e a desinformação sobre a sexualidade afetam a saúde sexual, comprometendo o alcance da plenitude da vida humana.

Conforme GARCIA (1993), DIAMANTINO et al (1993) e ABDO (2000) a função sexual excede na espécie humana os aspectos orgânicos, sendo dependente de fatores biopsicossociais. Os elementos que influenciam e que são influenciados pela sexualidade são: idade biológica, aspectos sócioculturais (situação conjugal/afetiva, emocional, espiritual, conhecimento e crenças a respeito da sexualidade, capacidade de identificação e comunicação das dificuldades sexuais), antecedentes pessoais (história de vida, iniciação sexual, evolução dos relacionamentos), estados de depressão e índices hormonais.

Quanto à questão "De acordo com os estudos sobre a sexualidade humana, atualmente existem tratamentos para casos de disfunções sexuais femininas. Você conhece algum?", 56,7\% das acadêmicas responderam que conheciam, 33,3\% que não conheciam e 10,0\% deixaram em branco.

Das acadêmicas que conheciam algum tratamento para casos de disfunções sexuais femininas, 45,8\% referiram o tratamento psicológico e $10,4 \%$ citaram tratamento para infertilidade e para ovários policísticos, que não se relacionam ao tratamento para as disfunções sexuais, demonstrando assim equívocos e falta de conhecimento sobre o assunto, como mostra a Tabela 3.

Tabela 3. Referências de acadêmicas de enfermagem sobre as formas de tratamento de disfunções sexuais femininas. Goiânia (GO), 2002.

\begin{tabular}{lll}
\hline Respostas & $\mathrm{f}$ & $\%$ \\
\hline Psicológico (terapias em grupo e individual, sexoterapia, auto-ajuda, meditação) & 22 & 45, \\
& 8 \\
Tratamento clínico (hormonal e medicamentoso) & 16 & 33,3 \\
Tratamento para infertilidade & 05 & 10,4 \\
Tratamento cirúrgico & 02 & 4,2 \\
Métodos de penetração artificial & 01 & 2,1 \\
Pomporismo & 01 & 2,1 \\
Educação sexual & 01 & 2,1 \\
\hline TOTAL & 48 & 100, \\
\hline
\end{tabular}

Segundo ABDO (2000) e SANDI (2000), na atualidade há tratamentos satisfatórios para as diversas disfunções sexuais, como tratamento clínico, cirúrgico e psicoterápico.

Para ABDO (2000), algumas primícias básicas devem ser consideradas antes de iniciar a terapia: o terapeuta deve estar bem com a sua sexualidade, atender aos aspectos éticos e considerar a interelação entre os distúrbios orgânicos e os psíquicos, a terapia deve ser do casal e com abordagem multidisciplinar (ginecologista, urologista e psicoterapeuta); a equipe deve funcionar como catalisadora para comunicação e descrição da base psicossocial das disfunções; devese reconhecer o temor da paciente em relação ao seu desempenho social e a seus preconceitos, tabus e princípios morais; estimular uma atitude de autoobservação (auto-exame, exploração dos genitais, exercícios específicos); relaxamento; apoio; tratamento da causa orgânica (medicamentoso, hormonal, uso de lubrificantes, cirúrgico e outros).

Quanto à questão "Como, quando e quais foram as primeiras informações que você obteve sobre disfunções sexuais femininas?", observou-se que 38,3 $\%$ das acadêmicas obtiveram as primeiras informações sobre disfunções sexuais femininas na própria instituição, sendo descritas na Tabela 4.

Ao se questionar quais foram as primeiras informações, as acadêmicas relataram temas que não se relacionam diretamente com as disfunções sexuais femininas, mas com outras questões ginecológicas, demonstrando certa dificuldade em diferenciar os problemas referentes à saúde da mulher, descritos a seguir: "Mulheres frígidas e dor durante a penetração do pênis", "Hemorragias vaginais abundantes", "Algumas "Vatologias", "Vaginismo", "Homossexualismo", "Saúde da Mulher" e "Orgasmo".

Tabela 4. Relatos de como foram obtidas as primeiras informações sobre disfunções sexuais femininas. Goiânia (GO), 2002. 
De acadêmicas de enfermagem sobre disfunções sexuais femininas. Revista Eletrônica de Enfermagem, v. $07, \mathrm{n} .02, \mathrm{p} .138$ - $147,2005$. Disponível em http://www.fen.ufg.br

\begin{tabular}{llll}
\hline \hline Respostas & & f & $\%$ \\
\hline Instituição de ensino (seminário de antropologia, prática clínica, & 23 & 38,3 \\
trabalhos) & & & \\
Leituras complementares (entrevistas, jornal, revistas) & 13 & 21,7 \\
Televisão & 05 & 8,3 \\
Adolescência & 02 & 3,3 \\
Amigos & 01 & 1,7 \\
Escolas & 01 & 1,7 \\
Pré-nupcial & 01 & 1,7 \\
Trabalho & 01 & 1,7 \\
Em casa & 01 & 1,7 \\
Em branco & 12 & 20,0 \\
\hline TOTAL & & 0 & 100,0 \\
\hline
\end{tabular}

Na questão "Durante a graduação, você estudou as disfunções sexuais?", obteve-se $43,2 \%$ de afirmação, $53,2 \%$ de negação e $3,2 \%$ não fizeram nenhuma alusão.

Ao responder "Durante a graduação, você estudou as disfunções sexuais? Qual disciplina?", 26 acadêmicas do total de 60 apontaram Saúde da Mulher e Obstetrícia $(30,0 \%)$ como sendo a disciplina em que mais abordou-se o assunto, $6,7 \% \mathrm{fez}$ referência a Antropologia e $6,7 \%$ a Fisiologia.

Segundo GARCIA (1993), o ser humano deve ser considerado em sua totalidade. A enfermagem tem, tradicionalmente, feito essa consideração, quando planeja e promove uma assistência holística. Para isso, BISON (1998) e BENTO (2000) reforçam a necessidade do curso de graduação fornecer meios favoráveis e satisfatórios para os universitários desenvolver conhecimentos e habilidades com o espírito analítico e reflexivo a respeito de si mesmos e dos outros, trabalhando estas questões, clara e objetivamente, de modo a propiciar instrumentalização e meios adequados para a garantia do fortalecimento de valores estruturais e psico-emocionais.

$\mathrm{Na}$ pergunta "A graduação proporcionou a aquisição de conhecimentos sobre sexualidade?", das 60 acadêmicas 38,3\% referiram não ter adquirido conhecimento sobre sexualidade durante a graduação, o que confirma os dados apresentados acima quanto a resposta "Durante a graduação, você estudou as disfunções sexuais?", como mostra a Tabela 5.

Tabela 5. Respostas referentes à aquisição de conhecimento sobre sexualidade durante a graduação. Goiânia (GO), 2002.

\begin{tabular}{lll}
\hline Respostas & $\mathrm{f}$ & $\%$ \\
\hline Sim & 23 & 38,3 \\
Não & 15 & 25,0 \\
Muito pouco (precário, quase nada, superficial, subjetiva) & 21 & 35,0 \\
Em branco & 01 & 1,7 \\
\hline TOTAL & 60 & 100,0 \\
\hline
\end{tabular}

BISON (1998) refere que a não inclusão explícita da temática "sexualidade humana" nos currículos mínimos constituiu-se uma omissão histórica, tradicionalista e moralista. EGRY (1985) apud GIR et al (2000), ao investigar o ensino da sexualidade humana em uma escola de enfermagem observou a inexistência da temática na estrutura curricular, ausência de preocupação em ministrar este ensino e, ainda, a incapacidade dos docentes investigados para assumir tal responsabilidade.

De acordo com GARCIA (1993), ao estudante de enfermagem devem ser garantidos o espaço, e também os instrumentos que lhe permitam compreender as dimensões e a historicidade dos fenômenos sociais, assim como a sua dinâmica, a fim de tornar possível a sua aproximação e intervenção na realidade para que a prática profissional do enfermeiro seja transformadora.

De acordo com NEIVA (2002), as questões sexuais femininas também continuam a ser um tabu para o profissional de saúde. MIRANDA (1994) apud
BANDEIRA \& OLIVEIRA (1998), ressaltam que essa resistência em discutir sobre a sexualidade na prática assistencial do enfermeiro existe desde a época de Nightingale, precursora da enfermagem moderna, período em que o paciente era considerado assexuado embora recebesse cuidados desde higiene até determinadas técnicas de preparo para exames.

Segundo GIR et al (2000), o enfermeiro é um profissional que tem oportunidade de assistir a grupos variados de pessoas (crianças, adolescentes, adultos e idosos), em situações diversas de saúde ou doença, no meio comunitário, ambulatorial ou hospitalar, independente de sexo, cor, raça e nível sócioeconômico e cultural.

Quanto a questão, "Você se considera preparada para trabalhar questões de sexualidade, principalmente disfunções sexuais durante a assistência de enfermagem?", 80,0\% das acadêmicas responderam que não se sentiam preparadas.

Este resultado mostra uma provável dificuldade de se trabalhar questões referentes à sexualidade no 
ARTIGO ORIGINAL

futuro profissional. Principalmente, porque $15,0 \%$ das acadêmicas referiram sentirem-se preparadas para trabalhar essas questões durante a assistência de enfermagem (tabela 6) e 43,2\% relataram ter estudado sobre as disfunções sexuais durante a graduação e $38,3 \%$ relataram ter adquirido conhecimento em sexualidade humana durante a graduação (tabela 5).

Tabela 6. Respostas referentes à preparação pessoal para trabalhar questões de sexualidade durante a assistência de enfermagem. Goiânia (GO), 2002.

\begin{tabular}{cll}
\hline Resposta & $f$ & $\%$ \\
\hline - Sente preparada & 09 & 15,0 \\
- Não sente preparada & 48 & 80,0 \\
- Em parte (precisa atualizar mais) & 02 & 3,3 \\
- Em branco & 01 & 1,7 \\
\hline TOTAL & 60 & 100,0 \\
\hline
\end{tabular}

Conforme RAFFERTY (1995) apud BISON (1998), embora os enfermeiros se deparem na atualidade com uma crescente demanda sobre questões sexuais embutidas na ação do cuidar, dificilmente abordam aspectos da dimensão sexual e mesmo as influências da doença, da terapêutica e do emocional sobre o exercício da sexualidade. A maior parte das escolas não trabalha essa questão adequadamente.

Segundo GARCIA (1993), uma das razões para a aparente inabilidade do enfermeiro em abordar aspectos da sexualidade humana durante a assistência, está relacionada à ausência desse conteúdo no currículo do curso de enfermagem.

CANO \& FERRIANI (2000) ressaltam que os profissionais de saúde que se propõem a trabalhar com grupos de adolescentes nas unidades básicas de saúde, escolas ou centros comunitários sabem que a questão que emerge com muito significado nas discussões é a sexualidade. Daí a necessidade de conhecer melhor os mitos, tabus e a realidade da sexualidade para abordá-la de forma mais tranqüila com os adolescentes, de manter um diálogo franco e entender a manifestação dessa sexualidade aflorada, própria da idade.

GARCIA (1993) afirma que o graduando de enfermagem, ao iniciar o curso já traz informações sobre sexualidade, marcada pelas ações da educação sexual, desde o nascimento. Por isso, enquanto seus próprios sentimentos, atitudes, crenças, valores, conceitos ou comportamentos a respeito da sexualidade não estiverem claros, ele não se sentirá seguro para abordar o assunto com a clientela no futuro profissional.

Assim, o estudo da sexualidade humana deve ser incluído no currículo de formação do enfermeiro. Pois, aprender a lidar com problemas que envolvem a sexualidade deve ser considerado tão importante quanto qualquer outro aspecto da problemática da clientela.

A sexualidade é indissociável da estrutura mental do sujeito, envolve a integridade dos níveis biológicos, psicológicos e psicossociais. Por isso, deve ser entendida como um processo intrínseco do ser em que representa muito mais que o ato sexual em si, pois que muitas vezes, o sexo é um ato fisiológico e sexualidade a totalidade do ser (FOUCAULT, 1985; ABDO, 2000; BUENO, 2001).

Conforme ANDRADE \& MELLO (1993), o estudo científico da sexualidade humana é bastante recente. Isto faz com que a própria formação dos diversos profissionais da área da saúde e da educação, que atuam junto às pessoas tanto na prevenção quanto no tratamento dos diferentes distúrbios e disfunções emocionais e orgânicas, nos mais diferentes níveis, seja deficiente. É difícil entender que nos dias atuais ainda existam escolas, enfim, de todos os cursos universitários, que não ofereçam no seu currículo normal temas referentes à sexualidade humana.

GIR et al (2000) afirmam que a enfermagem insere-se dentro do contexto sócio-cultural e, portanto, dele não difere quanto às crenças, mitos e tabus.

LEWIS \& BOR (1994) apud GIR et al (2000), ao pesquisarem a correlação entre conhecimento, conduta e práticas de enfermagem no contexto da sexualidade humana, obtiveram relatos de dificuldades em discutir sexualidade humana em 54\%; questionamento raro ou ausente sobre a sexualidade do paciente em 64\%; e de relevância em incluir questões sobre a história sexual do paciente em sua ficha de admissão em $54 \%$ dos relatos.

PELÁ et al (1995) apud GIR et al (2000), ao pesquisar o conhecimento de 147 enfermeiros de um hospital-escola sobre sexualidade, observaram que $25 \%$ dos profissionais receberam abordagem sobre o conteúdo em sua formação acadêmica, conseguindo orientar e esclarecer seus pacientes sobre questões sexuais.

Mesmo assim, GIR et al (2000) têm presenciado, no desenvolver das atividades do enfermeiro, dificuldade na abordagem da sexualidade. Imagine o acadêmico de enfermagem ao levantar a história do paciente.

SILVEIRA (1993), ao avaliar o nível de conhecimento sobre sexualidade entre acadêmicos de medicina e de engenharia, verificou que apresentavam nível semelhante de conhecimento, no período final de graduação.

As respostas da questão "Você já vivenciou alguma situação acadêmica que exigiu seu conhecimento sobre sexualidade humana?", encontradas na Tabela 7, mostram que $40,0 \%$ das acadêmicas haviam vivenciado alguma situação que 
exigiu conhecimento sobre a temática em questão durante as ações de enfermagem.

Tabela 7. Respostas de acadêmicas de enfermagem referentes às situações que exigiram conhecimento sobre sexualidade humana. Goiânia (GO), 2002.

\begin{tabular}{cll}
\hline Respostas & $\mathrm{f}$ & $\%$ \\
\hline - Já vivenciou & 24 & 40,0 \\
- Não vivenciou & 35 & 58,3 \\
- Em branco & 01 & 1,7 \\
\hline TOTAL & 60 & 100,0 \\
\hline
\end{tabular}

As situações acadêmicas que exigiram conhecimento sobre sexualidade humana segundo as referências dos sujeitos da pesquisa foram: "Orientação para saber como fazer para sentir prazer na relação", "Paciente com CA de reto, que teve que retirar a vagina", "Paciente com dificuldade nas relações por ter vagina fechada, sem comunicação com o útero e de $2 \mathrm{~cm}$ de extensão", "Durante o exame colpocitológico, a paciente disse da dificuldade em relação a sua sexualidade", "Durante o exame colpocitológico, foi questionada sobre disfunções sexuais", "Eu mesma estou vivenciando" e "Interferência de um procedimento cirúrgico no desempenho sexual" e "Paciente com dispareunia" .

Houve somente um relato de dificuldade na vivência da própria sexualidade, mostrando que os problemas no âmbito da sexualidade estão presentes entre as acadêmicas.

Segundo ABDO (1989), em pesquisa realizada com acadêmicos da Universidade de São Paulo, atendidos no setor de saúde e higiene mental, obteve uma significativa incidência de distúrbios, tais como: impotência sexual, ejaculação precoce, frigidez, homossexualismo, bissexualidade, dor na relação sexual, dentre outros.

\section{c) Importância do conhecimento das disfunções sexuais para formação profissional do enfermeiro}

$\mathrm{Na}$ questão "Você considera importante o conhecimento das disfunções sexuais para o seu desempenho profissional?", 96,6\% das acadêmicas consideraram importante 0 conhecimento das disfunções sexuais, $1,7 \%$ não consideraram importante e 1,7\% não responderam a questão.

As justificativas quanto à importância do conhecimento das disfunções sexuais são diversificadas como se vê nos relatos: "É uma realidade que vivenciaremos constantemente", "Para estar ajudando e ser ajudado também", "A cada dia mais pacientes procuram por respostas", "Considerando que o paciente deve ser visto como um ser completo, holístico", "Somos seres holísticos, portanto todos os fatores interferem no nosso dia-adia, sejam eles sociais, culturais, econômicos, sexuais e psicológicos", "Para melhor atendimento ao cliente", "Para podermos esclarecer dúvidas de clientes portadores e auxiliar no tratamento", "Em nossas consultas de enfermagem deve-se abranger este assunto", "Como irei orientar uma mulher ou até mesmo conhecer o que acontece comigo se não conheço as disfunções", "Para que exerçamos a conduta certa", "Ao conhecer as disfunções fica mais fácil identificar o problema e lidar com o mesmo", "São situações vividas por várias pessoas, em sigilo, podendo nós como profissionais auxiliá-las", e "Se um cliente apresentar tal problema, não sei como agir, nem o que orientar".

SAISI (1984) apud ABDO (2000), em estudo realizado com acadêmicos do curso básico da Pontifícia Universidade Católica de São Paulo sobre sexualidade humana, observou contradições entre o dito e o vivido no plano sexual. O discurso destes jovens, mostrou-se apenas ideológico: ao mesmo tempo, afirmando, negando e ocultando conflitos.

"Você considera importante a introdução de conteúdos ou de uma disciplina sobre sexualidade na grade curricular de Enfermagem?", foi a última pergunta do questionário. 95,0\% das acadêmicas consideram importante a introdução de conteúdos ou de uma disciplina sobre sexualidade na grade curricular da enfermagem, 1,7\% não consideram importante e 3,3\% não responderam a questão.

As justificativas quanto à importância da introdução de conteúdo ou de disciplina na grade curricular sobre sexualidade foram: "Para sermos em primeiro lugar mulheres, enfermeiras e grandes profissionais", "É importante na área da saúde", "Para que no futuro não tenhamos mais tabus de nossos antecedentes", "A abordagem é insuficiente", "Como futuros enfermeiros é de nossa competência termos noções e conhecimentos sobre o assunto", "Se não informar fora, a faculdade não traz grandes informações", "A sexualidade faz parte do ser humano e temos que entendê-lo como um todo", "Necessário para educação em saúde", "Desta forma poderíamos auxiliar as mulheres que sofrem deste problema, que sofrem preconceito em relação aos seus maridos e comunidades", "É um ponto falho na nossa grade curricular, especialmente porque um dos programas de atuação da enfermagem é a saúde da mulher", "Para que possamos encarar os assuntos relacionados à sexualidade com mais naturalidade" e "Para nos dar suporte para exercer a profissão".

Somente uma acadêmica não considerou importante a introdução de conteúdo ou de uma disciplina sobre sexualidade na grade curricular da enfermagem. Ela fez a seguinte referência: "Existem conteúdos mais importantes como emergência, fisiologia e farmacologia".

Segundo GARCIA (1993), aprender e ensinar sobre sexualidade, incluindo assim as disfunções 
sexuais proporciona ao enfermeiro meios e ações adequados para lidar com a amplitude desta questão. O enfermeiro deve ter consciência de que este tema é tão importante quanto qualquer outro aspecto relacionado à problemática saúde/doença da clientela.

GABALDON (1980) apud ABDO (2000), refere que no Brasil, os adolescentes carecem até hoje de informação sobre sexualidade, pois na maioria das vezes não é oferecida na família, nem na escola, mesmo diante da precocidade de iniciação da vida sexual.

Para ABDO (2000), a educação constitui-se num instrumento efetivo para se atingir a sexualidade responsável e satisfatória. Cabe ao educador sexual, além do domínio teórico da sexualidade humana, possuir razoável conhecimento e resolução de sua própria sexualidade, para saber abordar as questões sexuais.

GIR et al (2000), acreditam-se que independentemente da forma como a sexualidade foi abordada na infância e adolescência do indivíduo, a escola ou a universidade tem importante papel na formação de uma visão holística do homem, quer para sua atuação enquanto profissional quer para sua auto compreensão.

Nesse sentido, o enfermeiro bem fundamentado de conhecimentos sobre sexualidade terá competência para realizar educação sexual nas diferentes etapas do ciclo da vida, em condições normais ou patológicas, buscando auxílio junto a outros profissionais, a fim de garantir uma assistência multiprofissional. Para tanto, o estudo da sexualidade humana deve ser inserida no plano geral da educação podendo, na faculdade, refletir e discutir o tema em níveis mais profundos e objetivos.

Segundo FERREIRA \& FIGUEIREDO (1997), a sexualidade vem sendo tratada no discurso teórico da enfermagem, como uma necessidade humana básica. Mas, na prática, ela tem sido abordada junto à função reprodutiva, à fisiologia e aos problemas de ordem clínica e patológica. Não há ainda uma discussão crítica e contextualizada que contemple questões ligadas à esfera sócio-cultural da sexualidade humana.

\section{CONCLUSÕES}

Conforme os resultados obtidos, constatou-se que o conhecimento das acadêmicas de enfermagem sobre as disfunções sexuais femininas, como também sobre sexualidade humana, em ambas as instituições, é parcial e insuficiente, devido ao conteúdo não ser abordado na graduação pela especificidade. Quanto à importância para a formação profissional do enfermeiro, constatou-se a necessidade de sua abordagem para atuação na assistência à saúde da mulher.

Nesse sentido, concluiu-se que é pertinente a introdução de uma disciplina sobre sexualidade humana no curso de graduação em enfermagem, para que o profissional enfermeiro promova assistência global à saúde da mulher.

\section{REFERÊNCIAS BIBLIOGRÁFICAS}

ARTIGO ORIGINAL

ABDO, C.H.N. Aspectos da sexualidade de uma população universitária. São Paulo: Editora Lemos, 1989.

ABDO, C.H.N. Sexualidade Humana e Seus Transtornos. São Paulo: Editora Lemos, 2000.

ABDO, C.H.N.. Sexualidade: relevância no meio universitário. Revista Paulista de Medicina. V.120, n. 6, p.282, nov. - dez., 1984.

ANDRADE, R.P.; MELLO, C. R. Formação em sexologia e educação sexual no BRASIL. Femina. V. 21 n.11, p.1199-1216, nov.,1993.

BANDEIRA, L.; OLIVEIRA, E.M. Representações de Gênero e Moralidade na Prática Profissional da Enfermagem. Revista Brasileira de Enfermagem. V. 51, n. 4, p.677-696, out./dez. 1998.

BENTO, I.C.B. Problematização e Pesquisa: ação em sexualidade, DST e Aids com universitários. 2000. Dissertação (Mestrado) Escola de Enfermagem de Ribeirão Preto, Universidade de Ribeirão Preto.

BISON, R.A.P. Representações sociais dos estudantes de enfermagem sobre sexualidade, numa experiência de ensino. 1998.223f. Dissertação (Mestrado) Escola de Enfermagem de Ribeirão Preto, Universidade de São Paulo, Ribeirão Preto.

BRASIL. Conselho de ensino, pesquisa, extensão e cultura. Resolução - $n^{\circ} .421$ de 1998b.

BRASIL. Ministério da saúde. Conselho Nacional de Saúde. Resolução n. 196 de 10 de Outubro de 1996. Diretrizes e normas regulamentares da pesquisa envolvendo seres humanos. Cadernos de Ética em Pesquisa. No. 1 Julho. Brasília, 1998a.

BUENO, S.M.V. Educação preventiva em sexualidade, DST - Aids e Drogas nas escolas - Pesquisa ação e compromisso social. 2001. 223 f. Tese (Livre Docência) Escola de Enfermagem de Ribeirão Preto, Universidade de São Paulo, Ribeirão Preto.

CANO, M.A.T.; FERRIANI, M.G.C. Sexualidade na adolescência: um estudo biológico. Revista Latinoamericana de Enfermagem. 8, n. 2, p.18-24, abril, 2000.

CAVALCANTI, C.. Tratamento Clínico das Inadequações Sexuais. São Paulo: Editora Roca, 1992.

DIAMANTINO, E.M.V. et al. Aspectos básicos da sexualidade humana na prática clínica. Parte II. Femina. V. 21, n.11, p.1152-1180, nov. 1993.

FERREIRA, M. S.; FIGUEIREDO, N.M.A. Expressão da sexualidade do cliente hospitalizado e estratégias para o cuidado de enfermagem. Revista Brasileira de Enfermagem. V. 50, n.1, p. 17-30, jan./mar. 1997.

FOUCAULT, M. História da sexualidade I: a vontade de saber. Rio de Janeiro: Biblioteca de Filosofia e História das Ciências, 1980.

GARCIA, T. R. Sexualidade humana: conhecimento necessário à formação do enfermeiro. Acta Paulista de Enfermagem. V. 6, n.1/4, p.39-42, jan./dez. 1993.

GIR, E.; NOGUEIRA, M. S.; PELÁ, N.T.R. Sexualidade Humana na Formação do Enfermeiro. Revista Latinoamericana de Enfermagem. V. 8, n. 2, p.33-40, abril, 2000. 
KAPLAN, H.S. A nova terapia do sexo. Rio de Janeiro: Editora Nova Fronteira, 1977.

MANNOCCI, J.F. Disfunções Sexuais: Abordagem Clínica e Terapêutica. São Paulo: Fundo editorial, 1995.

NEIVA, P. B. Muito silêncio: pouco prazer. Veja São Paulo. V. 35, n. 12, p.79-79, Mar., 2002.

POLIT, F.D.; HUNGLER, P. B. Fundamentos de pesquisa em Enfermagem. Porto Alegre: Ed. Artes Médicas, 1995.

SANDI, S.F. Reflexões sobre as disfunções sexuais e o orgasmo feminino. Jornal Brasileiro de Medicina. V. 78, n. 4, p.41-43, abril, 2000.

SILVEIRA, $\quad$ M. T. Formados de medicina: conhecimentos, comportamentos e atitudes frente à sexualidade. 1993. 244p. Dissertação (Mestrado) Faculdade de Educação da Universidade Federal de Goiás, Goiânia.

Texto original recebido em 13/10/2004

Publicação aprovada em 10/02/2005 